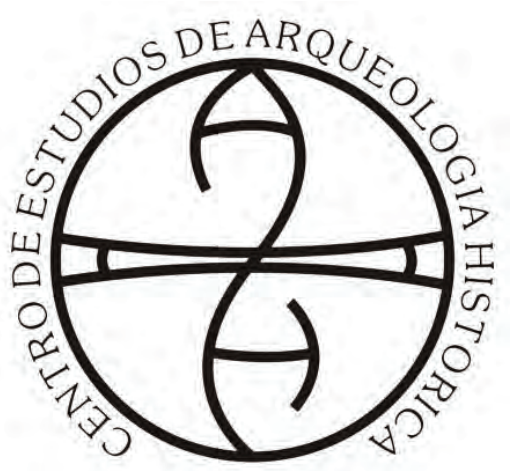

Centro de Estudios de Arqueología Histórica

Universidad Nacional de Rosario

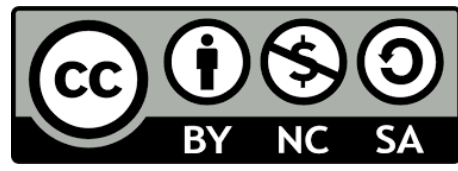

Teoría y Práctica de la Arqueología Histórica

Latinoamericana | Especial: Documentos de Trabajo |

Año I, Número 1 | 2020

Revista del Centro de Estudios de Arqueología Histórica, Facultad de Humanidades y Artes, Universidad Nacional de Rosario https://teoriaypracticaah.unr.edu.ar/index.php/index https://rephip.unr.edu.ar/handle/2133/14804

ISSN en línea: 2591-2801

ISSN versión impresa: 2250-866X

Atribución-NoComercial-CompartirIgual 4.0 Internacional (CC BY-NC-SA 4.0)

https://creativecommons.org/licenses/by-nc-sa/4.0/deed.es

Flavio Ribero (ID.: https://orcid.org/0000-0003-0198-

9458). Sitios arqueológicos rurales en campos serranos del suroeste de la provincia de Córdoba, Argentina

\title{
SITIOS ARQUEOLÓGICOS RURALES EN CAMPOS SERRANOS DEL Suroeste de la provincia de Córdoba, Argentina
}

\author{
Flavio Ribero *
}

\section{Resumen}

Esta presentación aborda investigaciones sobre sitios arqueológicos rurales en el sur de la Sierra de Comechingones, Departamento de Río Cuarto, Provincia de Córdoba. Durante la época tardocolonial, más de un tercio de la población del Curato del Río Cuarto vivía en los campos serranos, principalmente en el piedemonte. Las investigaciones arqueológicas de sitios rurales en la región serrana comenzaron en la región a fines de los noventa. Los sitios localizados hasta ahora poseen una ubicación cronológica situada entre 1770 y 1970 y diferentes estados con relación al avance de investigación en cada uno de ellos. Se presenta una caracterización general de los estudios realizados en un polígono que se extiende por la sierra, el piedemonte y en torno a los cerros aislados del confín de la Sierra de Comechingones, demarcándose etapas en su desarrollo.

Palabras clave: Arqueología rural, campos serranos, Sierra de Comechingones.

\section{Abstract}

This presentation addresses research on rural archaeological sites in the south of the Comechingones

\footnotetext{
* Laboratorio - Reserva de Arqueología, Facultad de Ciencias Humanas, Universidad Nacional de Río Cuarto. Centro de Estudios de Arqueología Histórica, Facultad de Humanidades y Artes, Universidad Nacional de Rosario.

Proyecto Arqueología prehispánica e histórica en la formación del territorio surcordobés. Consolidación. Secretaría de Ciencia y Técnica, Universidad Nacional de Río Cuarto.

Proyecto Registros arqueológicos rurales a la vera del río Piedra Blanca, cuenca alta del río Cuarto, Sierra de Comechingones Sur. Ministerio de Ciencia y Tecnología de la Provincia de Córdoba.

E-mail: flavioribero@yahoo.com.ar
} 
Teoría y Práctica de la Arqueología Histórica Latinoamericana | Especial: Documentos de Trabajo

Año I, Número 1 | 2020 / ISSN en línea: 2591-2801 | ISSN versión impresa: 2250-866X

Mountains, Department of Río Cuarto, Province of Córdoba. During the late colonial period, more than a third of the population of the Curato del Río Cuarto lived in the mountain fields, mainly in the foothills. Archaeological investigations of rural sites in the highlands began in the region in the late 1990s. The sites located so far have a chronological location between 1770 and 1970 and different states in relation to the research progress in each of them. We present a general characterization of the studies carried out in a polygon that extends along the mountain range, the foothills and around the isolated hills of the border of the Comechingones Mountains, outlining stages in their development.

Keywords: Rural archaeology, mountain ranges, Comechingones Mountains.

\section{Introducción}

Las investigaciones arqueológicas que se ocupan de estudiar los restos dejados por pobladores rurales en la región serrana del Departamento Río Cuarto, Provincia de Córdoba, se desarrollan desde hace más de veinte años. La región sur de la Sierra de Comechingones tuvo desde los inicios de la conquista un poblamiento continuo que hasta el final de la época tardocolonial fue más numeroso que aquel situado en lallanura. La vida de estos pobladores ha dejado rastros que hoy se están investigando arqueológicamente en un marco general de escases de estudios sobre su historia local y regional.Son registros que poseen una alta complejidad, derivada de compartir suelos arqueológicos con pasados múltiples (Rocchietti y Ribero 2018) y un ambiente semiárido y ecotónico. Los estudios se realizan en un contexto de avance de la frontera agrícola que pone en riesgo la subsistencia de dichos registros, ubicados en su mayoría en el piedemonte.

Este trabajo presentauna caracterización general de los estudios arqueológicos llevados a cabo desde los últimos años del siglo XX sobre sitios rurales localizados en campos serranos del suroeste de la Provincia de Córdoba. Se desarrolla cómo se han abordado las investigaciones sobre contextos arqueológicos cuya formación se produjo por el trabajo de pobladores rurales desde el fin del siglo XVIII hasta pasado mediados del siglo XX. En este sentido, se distinguen dos etapas definidas por la forma en que se tomó conocimiento de la existencia de los sitios y, fundamentalmente, por las problemáticas que impulsaron sus estudios. Finalmente, se sintetizan resultados alcanzados en los sitios Las Stipas y Ánimas del Pantanillo -correspondientes a la primera etapa- y Casco Antiguo de Piedra Blanca -correspondiente a la segunda etapa-.

\section{La Arqueología Rural en la región serrana}

Las investigaciones de Arqueología Rural en Argentina están en sus inicios. El desarrollo de la Arqueología Histórica desde los noventa se volcó fundamentalmente hacia contextos urbanos, fuertes y fortines de las fronteras internas y campos de batalla. Un panorama de los últimos veinte años muestra el paulatino crecimiento de la Arqueología Rural, aunque las investigaciones se concentran mayormente en la faja territorial central del país (Brittez, 2002, 2004; Chiavazza, 2010; Landa C., Pineau, V., Montanari, E., Ciarlo, N. y Chiecchio, D., 2010; Ribero,2009, 2013, 2019; Rocchietti y Ribero, 2007, 2009, 2018; Rocchietti, A. M., Ribero, F. y Olmedo E.; Rocchietti, A. M., Olmedo, E. y Ribero, F. 2013; entre otros).

En la región que concierne a este trabajo, las investigaciones se han llevado adelante en un polígono que abarca el sur de la Sierra de Comechingones, en su pendiente oriental. La sierra en esta parte

Sitios arqueológicos rurales en campos serranos del suroeste de la provincia de

F. RIBERO 
posee mayor desarrollo latitudinal y termina perdiéndose en la llanura pampeana. Por el norte las investigaciones han llegado hasta el río San Bartolomé o de la Invernada, en tanto que al sur el límite es la jurisdicción del Pueblo de Chaján. Al oeste el filo o cumbre de la sierra, a la vez límite interprovincial Córdoba - San Luis, y al este el fin del piedemonte, comienzo de la llanura (Figura 1).

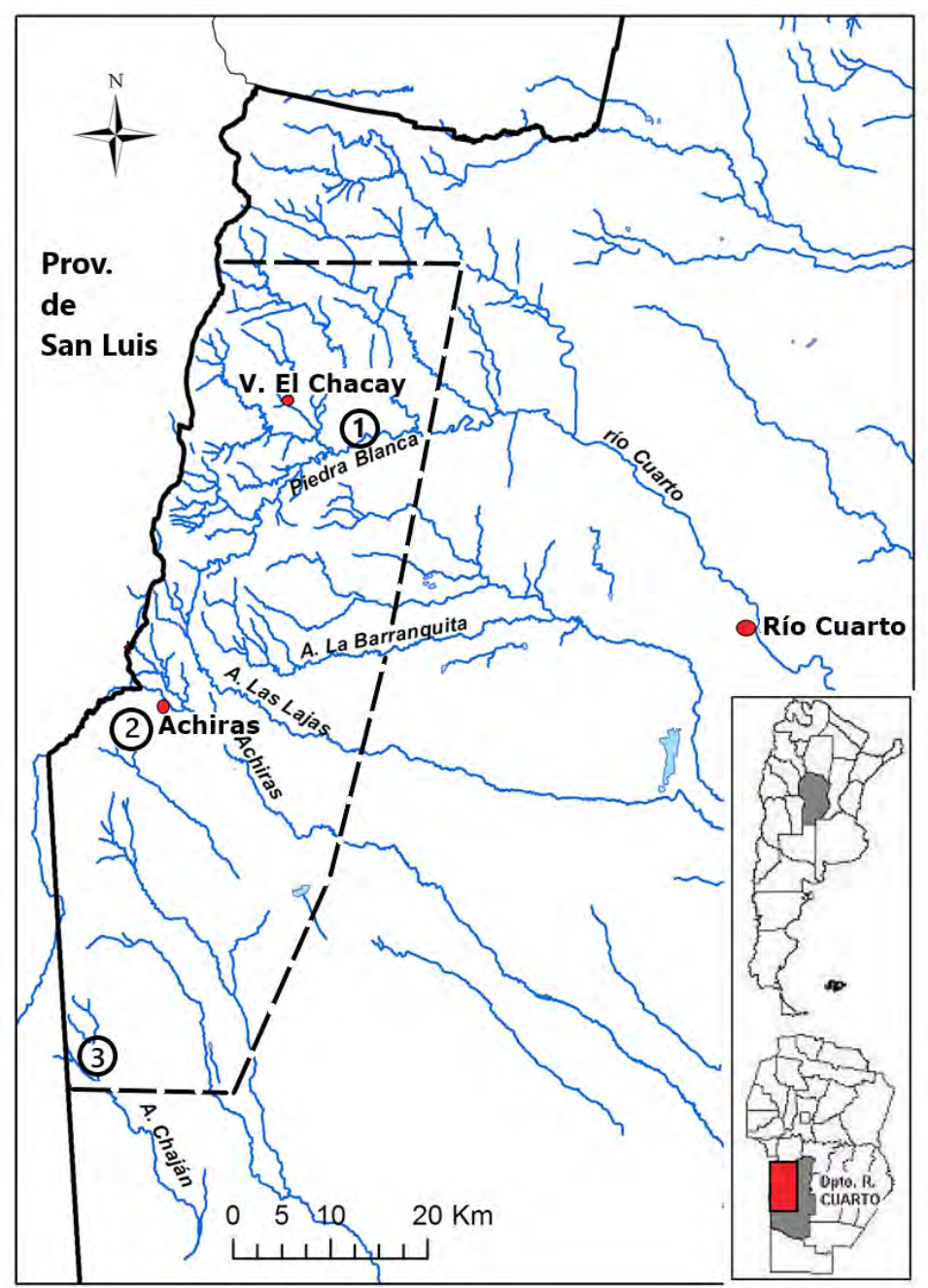

Figura 1. Ubicación del polígono de investigación y de los sitios abordados en este trabajo. La línea punteada señala los límites sur, este y norte del polígono, en tanto que el límite oeste lo constituye el límite interprovincial. 1) Sitio Casco Antiguo de Piedra Blanca. 2) Sitio Ánimas del Pantanillo. 3) Sitio Las Stipas.

Las investigaciones de Arqueología Rural dieron comienzo con las excavaciones de los sitios Las Stipas y Ánimas del Pantanillo en campañas efectuadas durante 2005-2006 para el primero y 20062009en el segundo. Hasta entonces, la localización de los restos fue aportada por vecinos de Chaján, y Achiras,quienes acercaron al equipo los datos o directamente lo condujeron hasta los mismos. Histo- 
Teoría y Práctica de la Arqueología Histórica Latinoamericana | Especial: Documentos de Trabajo Año I, Número 1 | 2020 / ISSN en línea: 2591-2801 | ISSN versión impresa: 2250-866X

riadores locales brindaron referencias documentales y orales -Luis Giacardi para Las Stipas y Miguel Ángel Gutiérrez para Ánimas del Pantanillo-. Posteriormente, se pudo ubicar documentación acerca de los sitios y en mayor medida de sus contextos locales y regionales. Esto último resultó más acentuado paraLasStipas, dondese evidenció la dificultad para asociar restos y documentos.

Estas investigaciones siguierona la efectuada en el sitio Fuerte Achiras (1832-1869), primera de Arqueología Histórica efectuada en la región. Éste, situado en un contexto urbano en la actualidad -la localidad de Achiras- puede ser considerado rural a la vez que militar en el marco de la existencia, en su tiempo, de la Frontera Sur de Córdoba. La excavación se realizó en campañas durante los años 19982000 (Austral y Rocchietti,1998;Rocchietti y Austral, 1999; Rocchietti, 2006, entre otras).Se contaba con la historia del Fuerte Achiras y del Pueblo en generalescrita por Gutiérrez (1983). En su obra y, en menor medida, en la de otros autores de la historiografía local y regional de los ochenta y noventa (Mayol Laferrère, 1977, 1981; Barrionuevo Imposti, 1986 a, b, 1988) había referencias a la población rural serrana de la región de Río Cuarto que en la excavación del Fuerte Achiras comenzó a plasmarse por primera vez como dato arqueológico. Entre otros hallazgos, se localizaron pisos de tierra, fogones, ladrillos de adobe, loza y objetos de metal en sectores del interior del fuerte -hoy Plaza Roca y Plaza del Mástil- donde la documentación refería la existencia de ranchos de la población civil resguardada tras los muros de piedra (Rocchietti y Austral, 1999).

Entre los aportes de los historiadores mencionados incluía la existencia de población rural serrana que se localizaba en una posición avanzada con respecto a la línea de fuertes y fortines. Posteriormente, comenzaron a surgir otros estudiossobre población,justicia y economía de la época tardocolonial (Bonet y Larrea, 2002; Bordese, 2008; Carbonari y Cocilovo, 2004; Rustán, 2005; Ribero, 2007; Wagner, 1997). Los mismos se inscribían en la línea de la renovación historiográfica sobre espacios rurales en regiones diversas de Argentina y el cono sur sudamericano que venía produciéndose desde mediados de los ochenta en el país. Estos trabajos basados en fuentes censales, inventarios, tasaciones y particiones de bienes, registros de alcabalas y libros de registros comerciales, empezaron a develar la existencia de población rural en la serranía que hasta el momento era solo conocida por haber sufrido los avatares de la vida en milicia, malones y guerras civiles.Esta renovación en las líneas de investigación histórica junto con el desarrollo de la Arqueología Histórica en Argentina y de los primeros trabajos de Arqueología Rural, hicieron crecer el interés por continuar la investigación arqueológica de sitios rurales emplazados en la sierra y su piedemonte, procediéndose al estudio de los ya mencionados sitios Las Stipas y Ánimas del Pantanillo, ambos formados durante la época tardocolonial y situados al sur de la línea fortinera.

En 2010 comenzó otra etapa en la investigación arqueológica integral de la región, llevando las prospecciones hacia la cuenca alta del río Cuarto, en una latitud menor a la hasta entonces investigada. En lo referente a la Arqueología Rural, se procuró georreferenciar todo tipo de vestigio rural con el fin de elaborar una base de datos que pudiera servir de punto de partida para una profundización de las investigaciones a futuro. Las prospecciones se realizaron siguiendo las márgenes de los ríos y arroyos, comenzando desde el piedemonte y avanzando hacia la sierra propiamente dicha. Uno de los principales cursos tomados como referencia fue el río Piedra Blanca y sus afluentes, los que fueron sistematizados en secciones y subsecciones con límites en topónimos reconocidos por los lugareños o en singularidades topográficas o de sus cauces.

Como resultado de las prospecciones se han localizado numerosos sitios que comprenden viviendas, corrales, pircados (de deslinde de potreros o propiedades), mojones de mensuras, diques, tomas de agua, acequias, molino hidráulico, canteras, socavones, instalaciones mineras (molienda de minerales, depósitos, vivienda de mineros, etc.) y constructivos sin función determinada. Desde 2017 se están es- 
Teoría y Práctica de la Arqueología Histórica Latinoamericana | Especial: Documentos de Trabajo Año I, Número 1 | 2020 / ISSN en línea: 2591-2801 | ISSN versión impresa: 2250-866X

tudiando selectivamente los localizados en el piedemonte. Entre éstos se destaca el Casco Antiguo de Piedra Blanca, al cual se abordará más adelante.

Las investigaciones arqueológicas en la cuenca alta del río Cuarto se están realizandoen un marco de escases de estudios históricos sobre la región en cuestión. Tal lo referido para el resto del sur de la Sierra de Comechingones, los estudios históricos de los ochenta y noventasolo la abordan tangencialmente y en relación a las líneas temáticas ya explicitadas anteriormente. Por otra parte, se repite el cuadro trazado para la región respecto a la renovación historiográfica, donde si bien algunos de los trabajos disponibles abarcan en parte la cuenca alta del río Cuarto, solo se refieren a su situación en el periodo tardocolonial. Tal panorama ha obligado a emprender un relevamiento documental en archivos locales y el Archivo Histórico de la Provincia de Córdoba que se encuentra en su fase inicial.

La localización de los sitios en el piedemonte es coincidente con la ubicación de las principales localidades serranas en la región bajo estudio, Achiras y Las Albahacas, El impreciso límite entre campo y ciudad se ha complejizado con el crecimiento de las zonas urbanizadas y el auge cobrado por el turismo en las últimas décadas. Sin embargo, la mayoría de lossitios están ubicados en los campos, propiedades privadas dedicadas a la cría de ganado -vacuno principalmente- y al cultivo de soja y maíz. El impacto de la circulación de turistas o de personas de la Ciudad de Río Cuarto y región que construyen sus casas de fin de semana es mínimo. En cambio, el grado de avance del desmonte en el piedemonte es prácticamente total hasta donde los afloramientos rocosos lo impiden. Aún los intersticios más estrechos entre afloramientos están siendo objeto de desmonte para la agricultura. Al cambio en el contexto de los sitios se suma el tránsito de maquinaria agrícola, con la apertura de caminos o huellas por donde circulan luego otros vehículos. Esto abre la posibilidad para el desmonte de las estructuras de piedra para eliminar "obstáculos" o con el fin de reutilización como materia prima en nuevas construcciones.

\section{El ambiente serrano}

Hacia el sur de Achiras la sierra se presenta en forma de cerros aislados y de baja altitud, predominando la cobertura sedimentaria -en parte medanosa- transición a la llanura plena. En cambio, desde la latitud de Achiras y hacia el norte existen dos ambientes litológicos, uno plutónico, con predominio de granitos y granitoides(Nullo, F. E., Fagiano, M. R. y Otamendi, J. 1992; Otamendi, J. E.; Fagiano, M. R., Nullo, F. E. y Castellarini, P. A. 2002) y otro metamórfico con dominancia de gneises (Fagiano, M., Nullo, F.; Otamendi, J. y Feliú, 1995; Otamendi, J. E.,Fagiano, M. R. y Nullo, F. E. 2000).

La región posee clima semiárido, con numerosos ríos y arroyos de régimen permanente. Desde el arroyo Cipión -algunos minutos más al norte que la latitud de Achiras- hacia el sur, se encuentra la cuenca de arroyos dispersos con tendencia de derrame hacia el SE -depresión de los bañados de la laguna La Amarga- infiltrándose en la llanuramedanosa(Vázquez et al., 1979). Al norte del $\mathrm{A}^{\circ} \mathrm{Cipión}$, en el ambiente litológico metamórfico, se encuentra la cuenca alta del río Cuarto, con el río Piedra Blanca y el río de Las Barrancas como cauces principales.

De norte a sur, bordeando la sierra, se encuentra el piedemonte. Es una franja de ancho variable, de 2 km promedio (Vischi y Arana, 2002; Kraus, T. A., Bianco, C. A. y Núñez, C. O.,1999),donde otrora había abundancia de algarrobo blanco y negro(Prosopis alba; Prosopis nigra). En los relictos que sobreviven del Espinal en la actualidad se encuentra Espinillo(Acacia caven), chañar (Geoffroeadecorticans), piquillín chico y grande (Condalia microphylla; Condalia buxifolia), moradillo y tala(Celtis tala). El límite al este llega hasta los 700 m.s.n.m. aproximadamente, donde los expertos en geomorfología señalan el comienzo de la llanura fuertemente ondulada (Degiovanni,2005).

Sitios arqueológicos rurales en campos serranos del suroeste de la provincia de

F. RIBERO 
Teoría y Práctica de la Arqueología Histórica Latinoamericana | Especial: Documentos de Trabajo

Año I, Número 1 | 2020 / ISSN en línea: 2591-2801 | ISSN versión impresa: 2250-866X

La abundancia de los recursos brindados por el ambiente serrano -además de la presencia de población indígena sedentarizada que fue sometida a régimen de encomienda- debe haber obrado a favor de su elección para los pobladores en tiempos históricos (Ribero, 2013, 2018). Para 1778, un tercio de la población del Curato del río Cuarto vivía en la región serrana (Carbonari y Cocilovo, 2004; Ribero, 2007, 2013). Parte de la población por entonces allí establecida se encontraba en una posición más avanzada latitudinalmente que los fuertes y fortines de la Frontera Sur de Córdoba (Ribero, 2007, 2010, 2013). Los sitios Las Stipas y Ánimas del Pantanillo se formaron en ese contexto.

\section{Sitios Las Stipas y Ánimas del Pantanillo}

Las Stipas se encuentra a la vera de uno de los brazos que forman las nacientes del $\mathrm{A}^{\circ} \mathrm{Chajány}$ próximo a dos cerros -Blanco y Negro- que son los más australes de la Sierra de Comechingones. Se trata de los restos que dejaron los habitantes del primer poblamiento de Chaján, del cual se tiene datos de su existencia para 1778, con el censo virreinal practicado en aquel año. En 1808 se llevó a cabo el Inventario, Tasación y partición de bienes de la Estancia de Chaján y en 1820 se reintegró una hijuela a una de las hijas que en 1808 era menor de edad (Ribero, 2007, 2011). Los datos de los propietarios de la Estancia son coincidentes entre el censo de 1778 y las fuentes de 1808 y 1820. Es probable que los restos hallan formado parte de la Estancia, quizás las viviendas de los propietarios o de población agregada a la misma. Se trata de dos recintos de planta rectangular y un corral de pircas.

Se excavó el recinto de mayor superficie y que conservaba relictos de los muros en un grado de integridad superior, pues el derrumbe de ambas estructuras era importante. Es probable que se trate de una de las primeras excavaciones arqueológicas de un contexto criollo rural en Argentina. Las paredes poseen un metro de espesor y no tienen cimientos; fueron construidas con piedras lajas -obtenidas de esquistos aflorantes en las inmediaciones- y mortero de barro. Sus dimensiones son 6.70 men su eje norte-sur y $3.34 \mathrm{~m}$ en el este-oeste. El edificio se levantó sobre un terreno irregular, con declive hacia el este, el cual fue salvado mediante un terraplén afirmado con piedras lajas dispuestas de canto, conformando una zapata que compensa el desnivel. La altura completa entre zapata y relicto de la pared del lateral este es de $2.26 \mathrm{~m}$. En el lateral oeste ha quedado parcialmente en pie una pared con un engrosamiento con forma de paralelepípedo que apoya sobre una de sus bases menores y que forma la columna de apoyo de la que fuera la abertura correspondiente a la puerta.Las paredes de los laterales norte y sur están a ras del suelo, habiéndose desmoronadas ambas hacia el exterior.

En su interior posee un depósito atravesado en su parte superior por las rocas del derrumbe, con una potencia de $0.60 \mathrm{~m}$ y de carácter guadaloso. En su parte inferior se halló un piso de tierra o consolidado duro. Se realizó un sondeo en el esquinero del noreste y una excavación posicional de tres metros por un metro y medio, estando su extensión determinada por el espacio muy reducido del interior de la habitación, que resulta del área no afectada por el derrumbe de parte de la mampostería hacia dentro. Tanto en uno como en la otra se constató la secuencia de un perfil estratigráfico que comprendía dos componentes. Uno superior, con vidrio muy fragmentado y un fogón que se atribuye al uso -esporádico o no- por vecinos o cazadores casuales, y otro inferior con cerámica criolla, una clavija con cabeza cuadrangular (de las que se emplearon en construcción hasta 1850), loza, vidrio y abundante hueso muy fragmentado, el cual -se estima- correspondería al nivel de la casa tardocolonial(Rocchietti y Ribero, 2007, 2008; Ribero, 2013; Rocchietti et al., 2013).

El sitio Ánimas del Pantanillo se encuentra ubicado a $6 \mathrm{~km}$ al oeste de la localidad de Achiras, próximo al límite interprovincial de San Luis y Córdoba. Pantanillo fue el paraje donde estuvo localizada

Sitios arqueológicos rurales en campos serranos del suroeste de la provincia de

F. RIBERO

Córdoba, Argentina

Páginas 41-52 
Teoría y Práctica de la Arqueología Histórica Latinoamericana | Especial: Documentos de Trabajo Año I, Número 1 | 2020 / ISSN en línea: 2591-2801 | ISSN versión impresa: 2250-866X

la primera posta de Achiras (1775?) (Gutiérrez, 1983), sobre el camino que vinculaba Buenos Aires con Cuyo y Chile, además de bifurcaciones que llevaban hacia Córdoba o que permitían entroncar con el Camino Real al Alto Perú (Barba, 1956; Barrionuevo Imposti, 1986 a). En el mismo paraje se edificó la capilla de Nuestra Señora de las Mercedes, posiblemente a fines del siglo XVIII.Referencia a la capilla se encuentra en el proyecto de división del Curato de Río Cuarto del obispo de Córdoba, Rodrigo Antonio Orellana, de diciembre de 1809. En El Pantanillo debía funcionar una Vice-Parroquia dependiente de la sede parroquial ubicada en Nuestra Señora de la Concepción de Río Cuarto (Barrionuevo Imposti, 1986 a; Costa, 1992). En los libros parroquiales de bautismos, matrimonios y defunciones del Curato de Río Cuarto se ha localizado información concerniente a la misma (Tamagnini, M., Olmedo, E., Pérez Zavala, G. y Ribero, F. 2010). El nombre del sitio hace referencia a la expresión que usaban los lugareños cuando hablaban de los restos humanos que solían aparecer en superficie desenterrados por algún animal.

Se excavaron los restos de la capilla y otras estructuras anexas. La excavación estratigráfica reveló la existencia de varios conjuntos de cimientos y arranques de pared, los cuales fueron sistematizados en tres sectores, de los cuales el más íntegro fue el sector A, que contenía los restos de la capilla y otros dos recintos cercanos. Los restos de la capilla estaban enterrados y un túmulo demarcaba su existencia. La excavación reveló la existencia de dos recintos: uno que se ha identificado como Mayor (nave) y otro contiguo Menor. Uno y otro se distinguen por el grosor de las paredes. El recinto Mayor tiene una arquitectura de grandes piedras cuyos intersticios fueron rellenados con otras pequeñas; todas irregulares y transportadas desde las inmediaciones. La fábrica del recinto Menor consiste en grandes piedras clavadas sobre su cara más extensa y colocadas paralelas de a dos y relleno el volumen intermedio por piedras más pequeñas. El recinto Mayor posee planta rectangular de 13,50 m en sentido E-W y $6 \mathrm{~m}$ en el N-S, con muros de $1 \mathrm{~m}$ de ancho. Su interior está colmado de tumbas (de orientación norte-sur y este-oeste) mostrando una saturación del espacio que debió ser compensado con el uso del contorno de la iglesia -se encontraron restos humanos enterrados en el exterior, sobre el lateral norte-. Las tumbas llegan hasta el espacio destinado al altar y ábside. Salvo los entierros, es de destacar la ausencia de objetos en el contenido de la capilla(Aguilar y Ribero, 2011; Ribero, 2013; Rocchietti y Ribero, 2009; Rocchietti et al., 2012, 2013).

Los sitios de Las Stipas y Ánimas del Pantanillo son contextos arqueológicos del poblamiento tardocolonial de la región serrana, los cuales han sido objeto de análisis en otras oportunidades. Contextos de la segunda mitad del siglo XIX y primera mitad del siglo XX están en estudio actualmente. Se presenta a continuación uno de ellos, el Casco Antiguo de Piedra Blanca.

\section{Casco Antiguo de Piedra Blanca}

Este sitio está ubicado en la margen derecha del río Piedra Blanca, a 2,5 km lineales al oeste de la ruta provincial $\mathrm{N}^{\circ} 23$. Comprende un total de ocho constructivos que se levantan en un terreno plano a $200 \mathrm{~m}$ del río, en un sector donde éste hace una curva, haciendo que la distancia para acceder al mismo sea igual tanto hacia el noreste como hacia el oeste. Una acequia que tomaba agua del río Piedra Blanca, varios kilómetros río arriba,proveía al Casco, discurriendo su cauce a $80 \mathrm{~m}$ al noreste.

Los constructivos están separados en dos cuadros alambrados. Uno contiene seis edificios-tres viviendas, depósito, gallinero y fondo- y otro, dos corrales de pircas. A juzgar por la técnica constructiva las tres viviendas son contemporáneas. El arranque de pared es una mampostería de piedra -del gneis abundante en los afloramientos que se encuentran a menos de $100 \mathrm{~m}$ - y mortero de barro de $0,35 \mathrm{~m}$ de alto y $0,45 \mathrm{~m}$ de ancho, sobre la que se disponen hiladas de ladrillos de adobe con mortero de barro y

Sitios arqueológicos rurales en campos serranos del suroeste de la provincia de

F. RIBERO

Córdoba, Argentina

Páginas 41-52 
Teoría y Práctica de la Arqueología Histórica Latinoamericana | Especial: Documentos de Trabajo

Año I, Número 1 | 2020 / ISSN en línea: 2591-2801 | ISSN versión impresa: 2250-866X

revoque de cal y arena. Con el revoque del lado interno y externo el espesor de la pared es de 0,50 m. Una de ellas ha sido habitada hasta mediados de los años noventay las intervenciones que oportunamente se hicieron para acondicionarla se traslucen en un mejor estado de conservación en comparación con las demás, manteniendo algunas de las aberturas de maderay parte del techo a un agua de tirantes de madera y chapas. El techo de las otras dos viviendas y todas las aberturas han desaparecido. Al parecer, también lo tuvieron a un agua. Una diferencia entre la vivienda intervenida y las otras podría ser la altura de sus paredes $-4.35 \mathrm{~m}$ de altura máxima en estas- claramente menor en la primera, aunque no puede descartarse que en las obras de reacondicionamiento hayan reducido la altura de la misma.

El depósito tiene sus paredes construidas íntegramente con piedra y mortero de barro, en proporción mayor, gneis en forma de lajas y en menor medida, cantos rodados y bloques de cuarzo. Conserva parte del techo de tirantes de madera y chapas. El gallinero y el fondo poseen factura diferente. Están construidos con ladrillos cocidos y mortero de cemento, cal y arena. Han sido levantados con posterioridad a los demás edificios, posiblemente, contemporáneamente a cuando se realizaron las obras de acondicionamiento en la vivienda ya descripta.

La investigación está en curso. La cantidad y variedad de objetos recuperados en superficie ha sido escasa. Los sondeos practicados han arrojado idéntico resultado. A diferencia de los sitios tardocoloniales tratados anteriormente, las referencias documentales son escasas y no existen estudios históricos locales. Las referencias orales son prácticamente inexistentes. Esto es igual de válido para el Casco Antiguo como para otros sitios rurales que se han relevado en las cercanías del Casco Antiguo, la mayoría ubicados también en la margen derecha del río Piedra Blanca.

El propietario actual sostiene que su familia compró la propiedad en 1925. En el relevamiento documental en el Archivo de Catastro de Córdoba se ubicó la mensura de las tierras de la Estancia de Piedra Blanca que data de 1874. Según esta documentación y el croquis adjunto, las tierras donde está el Casco Antiguo formaban parte de la misma, cuya superficie total era de 44.762 has $0428 \mathrm{~m}$. Dada la ubicación óptima del casco, próxima al río Piedra Blanca y a pocos $\mathrm{km}$ de donde pasaba el Camino de la Costa -que bordeando las sierras de Córdoba unía la Ciudad de Córdoba con el camino de postas que pasaba por Achiras-se considera que éste pudo ser el casco de dicha estancia.

\section{Conclusiones}

Las investigaciones de Arqueología Rural que se han llevado a cabo en la serranía en los últimos veinte años han revelado la existencia de sitios cuya antigüedad se remonta desde el fin del siglo XVIII hasta las primeras décadas de la segunda mitad del siglo XX. La mayoría de estos se encuentran en el piedemonte. Son mayoritariamente constructivos despojados de objetos, lo cual podría explicarse por la pobreza general del estilo de vida que tuvieron sus pobladores o porque se retiraron tras su abandono. Las investigaciones se llevan a cabo en un marco de escasez de estudios históricos sobre la región, en especial para épocas posteriores a la tardocolonial. Los resultados obtenidos en las excavaciones de los sitios Las Stipas y Ánimas del Pantanillo, junto a las prospecciones que se están desarrollando permitirán a futuro ir formando una imagen territorial de la Arqueología Rural en el sur de la Sierra de Comechingones. Se pretende contribuir al conocimiento delas actividades domésticas y productivas de la población rural, las cuales han pasado a formar parte de una matriz compartida por sectores socialesconorígenes y status diversos en un espacio de frontera, generando un registro arqueológico dotado de complejidad.

Sitios arqueológicos rurales en campos serranos del suroeste de la provincia de

F. RIBERO 
Teoría y Práctica de la Arqueología Histórica Latinoamericana | Especial: Documentos de Trabajo

Año I, Número 1 | 2020 / ISSN en línea: 2591-2801 | ISSN versión impresa: 2250-866X

\section{Referencias bibliográficas}

AGUILAR, Y. y RIBERO, F. (2011). El patrimonio cultural y su capacidad de gestión: El sitio arqueológico “Ánimas del Pantanillo”. En Mayol Laferrère, C, Ribero, F. y J. Díaz (comps.), Arqueología y Etnohistoria del Centro-Oeste Argentino (pp. 149-157). Río Cuarto, Universidad Nacional de Río Cuarto.

AUSTRAL, A. y ROCCHIETTI, A. M. (1998). Arqueología del Fuerte de Las Achiras. Cronía. Revista de Investigaciones de Ciencias Humanas, UNRC. 2(2), 232-241.

BARBA, E. (1956). Rastrilladas, huellas y caminos. Buenos Aires, Raigal.

BARRIONUEVO IMPOSTI, V. (1986 a). Historia de Río Cuarto. En la Época Hispánica y en la Independencia. Tomo I. Buenos Aires, Tipenc.

BARRIONUEVO IMPOSTI, V. (1986 b). Historia de Río Cuarto. Constitucionalismo y Liberalismo Nacional. Tomo III. Buenos Aires, Tipenc.

BARRIONUEVO IMPOSTI, V. (1988). Historia de Río Cuarto. El Autonomismo Cordobés y el Rosismo. Tomo II. Buenos Aires, Gráfica Hornos.

BONET, O. y LARREA, Z. (2002). Un Mercader de Campaña en los comienzos del Siglo XIX. Depto. de Imprenta y Publicaciones. Río Cuarto, Universidad Nacional de Río Cuarto.

BORDESE, M. E. (2008). Vagos, Cuatreros y Ociosos. Documentos para el Estudio de la Campaña del Río Cuarto (Siglo XVIII). Serie Documentos para la Historia de la Región del Río Cuarto. Río Cuarto, Universidad Nacional de Río Cuarto.

BRITTEZ, F. (2002). Investigaciones en Arqueología Rural: Sitio Vizcacheras (partido de Coronel Brandsen (Provincia de Buenos Aires). Campañas 1998-1999. Arqueología Histórica Argentina. Actas del Primer Congreso Nacional de Arqueología Histórica (pp. 395-405).Mendoza, Corregidor.

BRITTEZ, F. (2004). Arqueología Rural en el partido de Coronel Brandsen, Provincia de Buenos Aires. En Gradin, C. y F. Oliva (eds.), La región pampeana. Su pasado arqueológico (pp. 211-222). Santa Fe, Laborde.

CARBOnARI, M. R. y COCILOVO, J. A. (2004). La Población de 1778 en la Región del Río Cuarto (Córdoba, Argentina). Río Cuarto, Fundación de la Universidad Nacional de Río Cuarto.

CHIAVAZZA, H. (2010). Arqueología de un emplazamiento rural: Estancia San Pablo. Mendoza, Argentina (S. XVIII -XX). Revista de Arqueología HistóricaArgentina y Latinoamericana, 4: 135-168.

COSTA, I. (1992). Reducción y el Cristo de la Buena Muerte. Río Cuarto, ICALA.

DEGIOVANNI, S. (2005). Geomorfología regional. En Blarasin, M.; S. Degiovanni; A. Cabrera y M. Villegas (comps.), Aguas superficiales y subterráneas en el sur de Córdoba: Una perspectiva geoambiental (pp. 19-29). Río Cuarto, Universidad Nacional de Río Cuarto.

FAGIANO, M.; NULLO, F.; OTAMENDI, J. y FELIÚ, G. (1995). Geología del sur de la Sierra de

Sitios arqueológicos rurales en campos serranos del suroeste de la provincia de

F. RIBERO 
Teoría y Práctica de la Arqueología Histórica Latinoamericana | Especial: Documentos de Trabajo Año I, Número 1 | 2020 / ISSN en línea: 2591-2801 | ISSN versión impresa: 2250-866X

Comechingones como base para el estudio de sitios arqueológicos. En Rocchietti, A. M. (comp.), Primeras Jornadas de Investigadores en Arqueología y Etnohistoria del Centro- Oeste del País (pp. 89-92). Río Cuarto, Universidad Nacional de Río Cuarto.

GUTIÉRREZ, M. Á. (1983).Achiras Histórica.San Luis, Gráfica Pellegrino.

KRAUS, T. A., BIANCO, C. A. y NÚÑEZ, C. O. (eds.).(1999). Los Ambientes Naturales del Sur de la Provincia de Córdoba. Río Cuarto, Fundación de la Universidad Nacional de Río Cuarto.

LANDA C.; PINEAU, V.; MONTANARI, E.; CIARLO, N. y CHIECCHIO, D. (2010). Arqueología de los primeros colonos en el norte de La Pampa. Puesto San Eduardo, Dto. De Trenel (fines del siglo XIX y principios del XX). En Berón, M.; L. Luna; M. Bonomo; C. Montalvo; C. Aranda y M. Carrera Aizpitarte (eds.), V Congreso deArqueología de la Región Pampeana Argentina. MamulMapu: Pasado y presente desde la Arqueología Pampeana (pp. 453-463). Ayacucho, Buenos Aires, Libros del Espinillo.

MAYOLLAFERRÈRE, C. (1977). Fuertes y fortines de la Frontera Sur de Córdoba. Línea del Río Cuarto. Boletín del Instituto de Estudios Históricos “Lorenzo Suárez de Figueroa”, 3: 3-29.

MAYOLLAFERRÈRE, C. (1981).La primera colonización del Río Cuarto (1727-1761). DiarioPuntal, 11 de noviembre. Río Cuarto.

NULLO, F. E.; FAGIANO, M. R. y OTAMENDI, J. (1992). Geología y petrología de los granitoides del sur de la Sierra de Comechingones, Córdoba, Argentina. Museo Nacional de Ciencias Naturales de Madrid. Estudios Geológicos, 48 (5-5), 209-381.

OTAMENDI, J. E.; FAGIANO, M. R. y NULLO, F. E. (2000). Geología y evolución metamórfica del Complejo Monte Guazú, sur de la Sierra de Comechingones, provincia de Córdoba. Revista de la Asociación Geológica Argentina, 55 (3), 265-279.

OTAMENDI, J. E.; FAGIANO, M. R.; NULLO, F. E. y CASTELLARINI, P. A. (2002). Geología, petrología y mineralogía del granito Inti Huasi, sur de la sierra de Comechingones, Córdoba. Revista de la Asociación Geológica Argentina, 57(4), 389-403.

RIBERO, F. (2007). Pobladores en la vanguardia fronteriza de Córdoba: Chaján (1750-1869). En Rocchietti, A. M. y M. Tamagnini (comps.), Arqueología de la frontera. Estudios sobre los campos del sur cordobés (pp. 185-219). Río Cuarto, Universidad Nacional de Río Cuarto.

RIBERO, F. (2009). Vestigios materiales y documentales de Chaján. En Austral, A. y M. Tamagnini (comps.), Problemáticas de la Arqueología Contemporánea (1271-1277). Río Cuarto, Depto. de Imprenta y Publicaciones, Universidad Nacional de Río Cuarto.

RIBERO, F. (2010). Chaján, un caso de poblamiento temprano al sur del río Cuarto. Trabajo Final de Licenciatura. Inédito.

RIBERO, F. (2011). Una estancia tardocolonial en el confín de la Frontera Sur de Córdoba. Revista Sociedades de Paisajes Áridos y Semi-áridos, III(V), 227-242. Disponible en: http://www2.hum. unrc.edu.ar/ojs/index.php/spas

Sitios arqueológicos rurales en campos serranos del suroeste de la provincia de F. RIBERO 
Teoría y Práctica de la Arqueología Histórica Latinoamericana | Especial: Documentos de Trabajo Año I, Número 1 | 2020 / ISSN en línea: 2591-2801 | ISSN versión impresa: 2250-866X

RIBERO, F. (2013). Arqueología de la Frontera Sur: El poblamiento del Río Cuarto Arriba desde la doble perspectiva espacial de las Provincias de Córdoba y de San Luis. En Gascón, M. y M. J. Ots (eds.), Fronteras y Periferias en Arqueología e Historia (pp. 127-158). Buenos Aires, Dunken.

RIBERO, F. (2018). Arqueología Rural del sur de la Sierra de Comechingones (Provincia de Córdoba, Argentina). En XIII Coloquio Binacional Argentino-Peruano (7 y 8 de noviembre). Ciudad Autónoma de Buenos Aires, Centro de Investigaciones Precolombinas.

RIBERO, F. (2019). Sitio La Quinta. Arqueología rural de campos serranos. Revista Teoría y Práctica de la Arqueología Histórica Latinoamericana, VIII (9): 103-115.

ROCCHIETTI, A. M. (2006). Arqueología de la Frontera. En: Olmedo, E. y F. Ribero (comps.), Debates actuales en Arqueología y Etnohistoria (pp. 105-118). Río Cuarto, Universidad Nacional de Río Cuarto.

ROCCHIETTI, A. M. y AUSTRAL, A. (1999). El fuerte de Achiras: dos dimensiones de un registro arqueológico. En: Rocchietti, A. M. (comp.), Primeras Jornadas de Investigación Científica del Departamento de Historia (pp. 3-12). Río Cuarto, Universidad Nacional de Río Cuarto.

ROCCHIETTI, A. M. y RIBERO, F. (2007). Epílogo: El primer poblamiento de Chaján. En Rocchietti, A. M. y M. Tamagnini (comps.), Arqueología de la Frontera. Estudios sobre los Campos del Sur Cordobés (pp. 303-316).Río Cuarto, Universidad Nacional de Río Cuarto.

ROCCHIETTI, A. M. y RIBERO, F. (2008). El primer poblamiento de Chaján. En: Carrara, M. T. (comp.), Continuidad y Cambio Cultural en Arqueología Histórica.Actas del Tercer Congreso Nacional de Arqueología Histórica (pp. 250-257). Rosario, Universidad Nacional de Rosario.

ROCCHIETTI, A. M. y RIBERO, F. (2009). Achiras histórica. Arqueología Colonial en el Sur de Córdoba. Sociedades de Paisajes Áridos y Semi-áridos, 1(1), 147-164.

ROCCHIETTI, A. M. y RIBERO, F. (2018). Arqueología Histórica en contexto rural: Pasados múltiples. Teoría y Práctica de la Arqueología Histórica Latinoamericana, 7(7), 71-82.

ROCCHIETTI, A. M.; RIBERO, F. y OLMEDO, E. (2011). Arqueología de una frontera: La línea militar y los pobladores fronterizos en la frontera de las pampas. Argentina (Siglos XVIII-XIX). En: Ramos, M. S. y O. Hernández de Lara (eds.), Arqueología Histórica en América Latina. Perspectivas desde Argentina y Cuba (pp. 33-46). Luján, Programa de Arqueología Histórica y Estudios Pluridisciplinarios, Universidad Nacional de Luján.

ROCCHIETTI, A. M.; OLMEDO, E. y RIBERO, F. (2013). Arqueología de la Frontera. Lo vestigios de una sociedad de las pampas argentinas. Buenos Aires, Aspha.

ROCCHIETTI, A. M.; RIBERO, F. y OLMEDO, E. (2012). Arqueología de la línea militar y los pobladores fronterizos en la frontera de las pampas. Argentina (siglos XVIII - XIX). Bases para una arqueología de las fronteras. Teoría y Práctica de la Arqueología Histórica Latinoamericana,I(I), 151-167.

ROCCHIETTI, A. M.; OLMEDO, E. y RIBERO, F. (2013). Arqueología de la Frontera. Lo vestigios de una sociedad de las pampas argentinas. Buenos Aires, Aspha.

Sitios arqueológicos rurales en campos serranos del suroeste de la provincia de

F. RIBERO 
RUSTÁN, M. E. (2005). De Perjudiciales a Pobladores de la Frontera. Poblamiento de la Frontera Sur de la Gobernación Intendencia de Córdoba a fines del Siglo XVIII. Córdoba, Ferreyra.

TAMAGNINI, M., OLMEDO, E., PÉREZ ZAVALA, G. y RIBERO, F.(2010). Aportes del registro documental a la interpretación arqueológica: La Capilla del Pantanillo (Pedanía de Achiras) En: Bárcena, R. y H. Chiavazza (eds.), XVII Congreso Nacional de Arqueología Argentina (pp. 361-366). Tomo I. Mendoza. Fac.de Filosofía y Letras, Universidad Nacional de Cuyo.

VÁZQUEZ, J. B., LÓPEZ ROBLES, A. Y SOSA, D. F. (1979). Cáp. IV: Aguas; Primera parte. En: Vázquez, J. B.; Miatello, R. A. y M. E. Roqué (dir.), Geografía Física de la Provincia de Córdoba(pp. 139-195). Buenos Aires, Boldt.

VISCHI, N. Y ARANA, M. (2002). Utilidad de las Plantas del Espinal. Río Cuarto, Fundación de la Universidad Nacional de Río Cuarto.

WAGNER, D. (1997). La Región del Río Cuarto. Una frontera ganadera (fines del Siglo XVIII y comienzos del XIX). Trabajo Final de Licenciatura en Historia. Facultad de Ciencias Humanas, Universidad Nacional de Río Cuarto. Inédita.

Recibido: 28 de febrero de 2020.

Aceptado: 30 de junio de 2020 . 